\title{
Combined Bronchial Artery Embolization and Endobronchial Resection for Bronchial Carcinoid: A Safety and Feasibility Pilot Study
}

\author{
Matthew Salamonsen ${ }^{a}$ Rachid Tazi-Mezalek ${ }^{a}$ Rosa López-Lisbona ${ }^{a}$ \\ Noelia Cubero $^{a}$ Núria Baixeras $^{b}$ Joan Dominguez ${ }^{c}$ Jordi Dorca ${ }^{a}$ \\ Antoni Rosell ${ }^{a}$ \\ Departments of ${ }^{a}$ Respiratory Medicine, ${ }^{b}$ Pathology and ${ }^{c}$ Radiology, Bellvitge Hospital, Barcelona, Spain
}

\section{Key Words \\ Carcinoid tumour · Bronchoscopy · Therapeutic embolization · Lung neoplasms · Interventional pulmonology}

\begin{abstract}
Background: There is growing evidence to support bronchoscopic resection of well-circumscribed typical carcinoids. However, massive bleeding and risk of recurrence can potentially complicate this approach. Objectives: The aim of this study was to assess the safety and feasibility of endobronchial resection of carcinoids preceded by bronchial artery embolization. Methods: Five patients with centrally located typical carcinoids were recruited, 4 with a curative intent and 1 for palliation of a carcinoid with mediastinal invasion. All patients underwent selective embolization of the feeding bronchial artery $24-48 \mathrm{~h}$ prior to endobronchial resection, which was performed with a rigid bronchoscope and neodymium:yttrium-aluminium-perovskite laser. $\boldsymbol{R e}$ sults: Minimal bleeding was noted during tumour resection. After a median (range) follow-up of 20 (14-48) months, only the case with segmental extension of the tumour had local recurrence, which was treated successfully using cryotherapy (with negative endobronchial biopsies since), and no cases of metastatic spread occurred. One patient, in whom the
\end{abstract}

histopathological diagnosis was changed from typical to atypical carcinoid following resection, went on to have a surgical bilobectomy 3 months later. Extensive fibrosis was noted at the site of original tumour resection with no evidence of residual disease. Conclusions: Bronchial artery embolization prior to endobronchial resection of centrally located carcinoids is feasible and safe. The reduction in bleeding may facilitate and simplify the procedure. The possible application of this combined therapy to the management of atypical carcinoids warrants the design of a larger prospective clinical trial.

c) 2015 S. Karger AG, Basel

\section{Introduction}

Bronchial carcinoid tumours are a relatively rare type of neuroendocrine tumours, accounting for $1-2 \%$ of all primary lung malignancies [1]. They can be further classified into typical or atypical carcinoid tumours according to histological features [2]. While typical carcinoid tumours rarely metastasize and have an excellent prognosis with a long-term survival of $>90 \%$, atypical carcinoids are more aggressive with a 5 -year survival of $40-75 \%$ [3].

The gold standard treatment for bronchial carcinoids remains surgical resection [4], although there is growing

\section{KARGER}

E-Mail karger@karger.com

www.karger.com/res
(C) 2015 S. Karger AG, Basel

0025-7931/15/0911-0063\$39.50/0 
Fig. 1. Coronal CT (a) and endobronchial view (b) of a carcinoid tumour (black arrow) located in the right main bronchus.
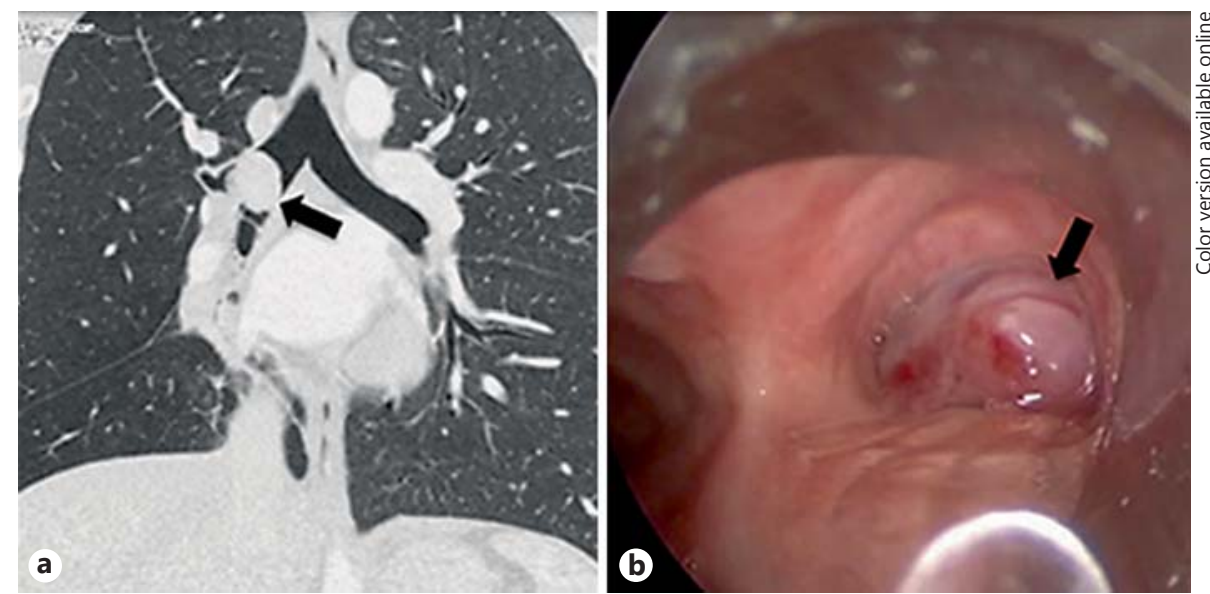

evidence to support bronchoscopic resection in selected cases of typical carcinoids and in those medically unfit to undergo surgery [5-8]. However, potential problems exist with endoscopic resection, such as the risk for major bleeding, necessitating urgent surgical intervention [9], or incomplete tumour removal, leaving residual disease [10]. To address these limitations, we performed a prospective safety and feasibility pilot study involving 5 patients who underwent endobronchial resection of a bronchial carcinoid tumour following arterial embolization of the corresponding bronchial artery.

\section{Materials and Methods}

This study was a prospective case series of 5 patients scheduled for endobronchial resection of a carcinoid tumour with a followup over a 5-year period (June 2010 to June 2015) at the interventional pulmonology unit of a tertiary hospital. The study was approved by the institutional ethics review board (reference No. PR222/14), and informed consent was obtained from each patient.

The decision for endobronchial management of all patients was made at an initial multidisciplinary lung cancer meeting, which consisted of pulmonologists, oncologists, radiologists and thoracic surgeons. All patients had a centrally located carcinoid tumour (fig. 1).

\section{Diagnosis}

All patients were assessed with contrast-enhanced multi-detector thoraco-abdominal computed tomography $(\mathrm{CT})$ and diagnostic bronchoscopy prior to treatment. The tumour was defined as typical or atypical according to the histological criteria of the World Health Organization [11].

\section{Bronchial Artery Embolization}

An initial angiographic survey was performed by an interventional radiologist to identify the bronchial artery branches that supplied the tumour. Selective arterial embolization of the corresponding arteries was then performed using foam particles (poly- vinyl alcohol 200-900 $\mu \mathrm{m}$ ) with or without microcoils (Cook Medical, Bloomington, Ind., USA).

\section{Bronchoscopic Resection}

All patients underwent rigid bronchoscopy $24-48 \mathrm{~h}$ after arterial embolization. Thermal coagulation of the tumour was initially performed with neodymium:yttrium-aluminium-perovskite (Nd: YAP) laser (Bryan Corporation, Woburn, Mass., USA) at 10-15 W before mechanical resection with the rigid bronchoscope (Efer Endoscopy, La Ciotat, France). In the case where there was evidence of residual tumour in the segmental bronchi following mechanical resection (patient 2), removal was completed piece-meal with a combination of rigid and flexible forceps.

The severity of intra-procedural bleeding was defined as negligible (controlled with topical cold saline and/or adrenaline alone), minor (requirement of a single repeat application of the laser), moderate (prolonged mechanical compression with the rigid bronchoscope or a balloon catheter and/or multiple repeat applications of the laser) or major (need for repeat arterial embolization or emergency surgery).

\section{Follow-Up}

All patients were followed up with chest CT and autofluorescence bronchoscopy (SAFE 3000, Pentax Corp., Tokyo, Japan), according to our protocol, at 2 and 6 months and then 6-monthly up to 5 years. Biopsies were routinely taken at the site of tumour resection if an abnormal autofluorescence signal was seen.

\section{Results}

Five patients were recruited for the study and followed-up for a median (range) of 26 (20-54) months. Four were male, and the average age was 60 years. Table 1 details the patient, tumour and treatment characteristics.

Dual endobronchial treatment was indicated in 2 patients unfit for surgery (patients 1 and 2), while one endobronchial treatment was indicated in a young patient 
Table 1. Patients' characteristics

\begin{tabular}{|c|c|c|c|c|c|c|c|c|c|}
\hline No. & $\begin{array}{l}\text { Age, } \\
\text { years/sex }\end{array}$ & Location & $\begin{array}{l}\text { Size, } \\
\mathrm{mm}\end{array}$ & Type $^{1}$ & $\begin{array}{l}\text { Extrabronchial } \\
\text { invasion }^{2}\end{array}$ & $\begin{array}{l}\text { Segmental } \\
\text { bronchi }\end{array}$ & $\begin{array}{l}\text { Degree of } \\
\text { bleeding }\end{array}$ & Recurrence & $\begin{array}{l}\text { Follow-up, } \\
\text { months }\end{array}$ \\
\hline 1 & $64 / \mathrm{M}$ & distal, LMB & $9 \times 11$ & typical & no & no & negligible & no & 38 \\
\hline 2 & $82 / \mathrm{M}$ & LLL, bronchus & $6 \times 9$ & typical & no & yes & minor & yes $^{5}$ & 20 \\
\hline 3 & $17 / \mathrm{M}$ & $\mathrm{RMB}$ & $20 \times 24$ & typical & no & no & negligible & no & 54 \\
\hline 4 & $77 / \mathrm{M}$ & mediastinum, RMB & $20 \times 27$ & typical & yes & no & negligible & no $^{6}$ & 26 \\
\hline 5 & $62 / \mathrm{F}$ & $\mathrm{BI}$ & $9 \times 23$ & atypical & no & no & minor & no & 24 \\
\hline
\end{tabular}

$\mathrm{LMB}=$ Left main bronchus; LLL = left lower lobe; $\mathrm{RMB}=$ right main bronchus; $\mathrm{BI}=$ bronchus intermedius. ${ }^{1}$ Type according to WHO classification. ${ }^{2}$ Radiological signs of infiltration through the bronchial wall on chest CT. ${ }^{3}$ Part of the tumour extending distally to the lobar bronchi. ${ }^{4}$ Negligible (controlled with topical cold saline and/or adrenaline alone), minor (requirement for a single application of repeat laser), moderate (prolonged mechanical compression with the rigid bronchoscope or a balloon catheter and/or multiple repeat applications of the laser), major (need for repeat arterial embolization or emergency surgery). ${ }^{5}$ Small focus detected by autofluorescence bronchoscopy, with negative biopsies following cryotherapy. ${ }^{6}$ Without recurrence of endoluminal disease, treatment was for palliation.

with a typical carcinoid (patient 3 ) to avoid a pneumonectomy, for palliation of a non-resectable relapsed carcinoid with mediastinal involvement (patient 4), and in a patient who had severe bleeding during the diagnostic bronchoscopy and in whom the initial diagnosis of typical carcinoid was changed to atypical carcinoid following a histopathological evaluation of the resected tumour (patient 5). Apart from the single patient with recurrent disease (patient 4), none had CT or positron emission tomography evidence of nodal or metastatic disease.

Bronchial arteriography could precisely identify the bronchial artery branches that supplied the tumours, and embolization was successfully performed in all patients without complications (fig. 2). In order to achieve haemostasis after resection, 3 patients only required topical adrenaline and cold saline, and 2 patients required repeat $\mathrm{Nd}$ :YAP laser; however, there were no cases who required more prolonged techniques for haemostasis, such as sustained forceful mechanical compression with the rigid bronchoscope or a gauze swab, inflation of a Fogarty balloon catheter or utilization of an endobronchial blocker.

Patient 5, in whom the diagnosis was changed from typical to atypical carcinoid following resection, went on to have a bilobectomy (right upper and middle) 3 months later, as this was considered the optimal management by the multidisciplinary team. The pathological examination of the surgical specimen revealed extensive ischaemic necrosis with no evidence of residual tumour in the excised lung or lymph nodes (fig. 3). During the followup period, there was 1 case of local recurrence (patient 2) successfully treated with cryotherapy (2.4-mm probe, ERBE, Tübingen, Germany).

Bronchial Artery Embolization and Endobronchial Resection

\section{Discussion}

To the best of our knowledge, we describe the first series of patients with bronchial carcinoids successfully treated by bronchial artery embolization followed by endobronchial resection. This treatment is safe and feasible, and we have found that it simplifies the procedure by reducing intra-procedural bleeding. It may also reduce the occurrence of residual tumour following the procedure, and the single case of successful treatment of atypical carcinoid raises the possibility of endobronchial resection for this more aggressive form of the disease, when combined with adjuvant treatments such as arterial embolization.

The reported incidence of major bleeding during endobronchial resection of carcinoid tumours varies and is difficult to clearly define. Although there are case series demonstrating the feasibility of endobronchial carcinoid resection without major haemorrhages [10], there are also consistent reports where a small proportion of patients have persistent or massive bleeding [8]. In a large series by Brokx et al. [12], problematic bleeding led to 1 of 72 patients having emergency surgery, and in another study, 1 of 24 patients had massive haemorrhage requiring emergency surgery [13]. A large review of 587 procedures found that the rate of emergency thoracotomy to control massive bleeding was $0.7 \%$ [14]. It may be that major haemorrhage predominantly occurs in the setting where there is a large arterial vessel in the stalk of the tumour which is cut during resection [9]. Although bronchial artery embolization is a well-established technique to manage massive haemoptysis [15], it can rarely be complicated by spinal cord ischaemia or infarction, with a reported major complica- 
Fig. 2. Angiographic and endobronchial views before (a) and after (b) bronchial arterial embolization of a carcinoid tumour situated in the right main bronchus. The successful embolization of the bronchial artery branch supplying the tumour (white arrow) can be seen in the angiographic views. a The carcinoid tumour can be seen (black arrow). Note the large amount of bleeding caused only by suction trauma before embolization compared with the minimal bleeding on biopsy with a rigid forceps after embolization.

Fig. 3. Histopathology of the endobronchially resected atypical carcinoid (a) and of the resected tumour in the surgical specimen 3 months later $(\mathbf{b})(\mathrm{HE}, \times 100)$. a Focal nuclear atypia with variation in size and shape, and areas of apoptosis and incipient necrosis (white arrow), characteristic of atypical carcinoid. $\mathbf{b}$ There is an area of scar fibrosis in the mucosa right out to the bronchial surface.
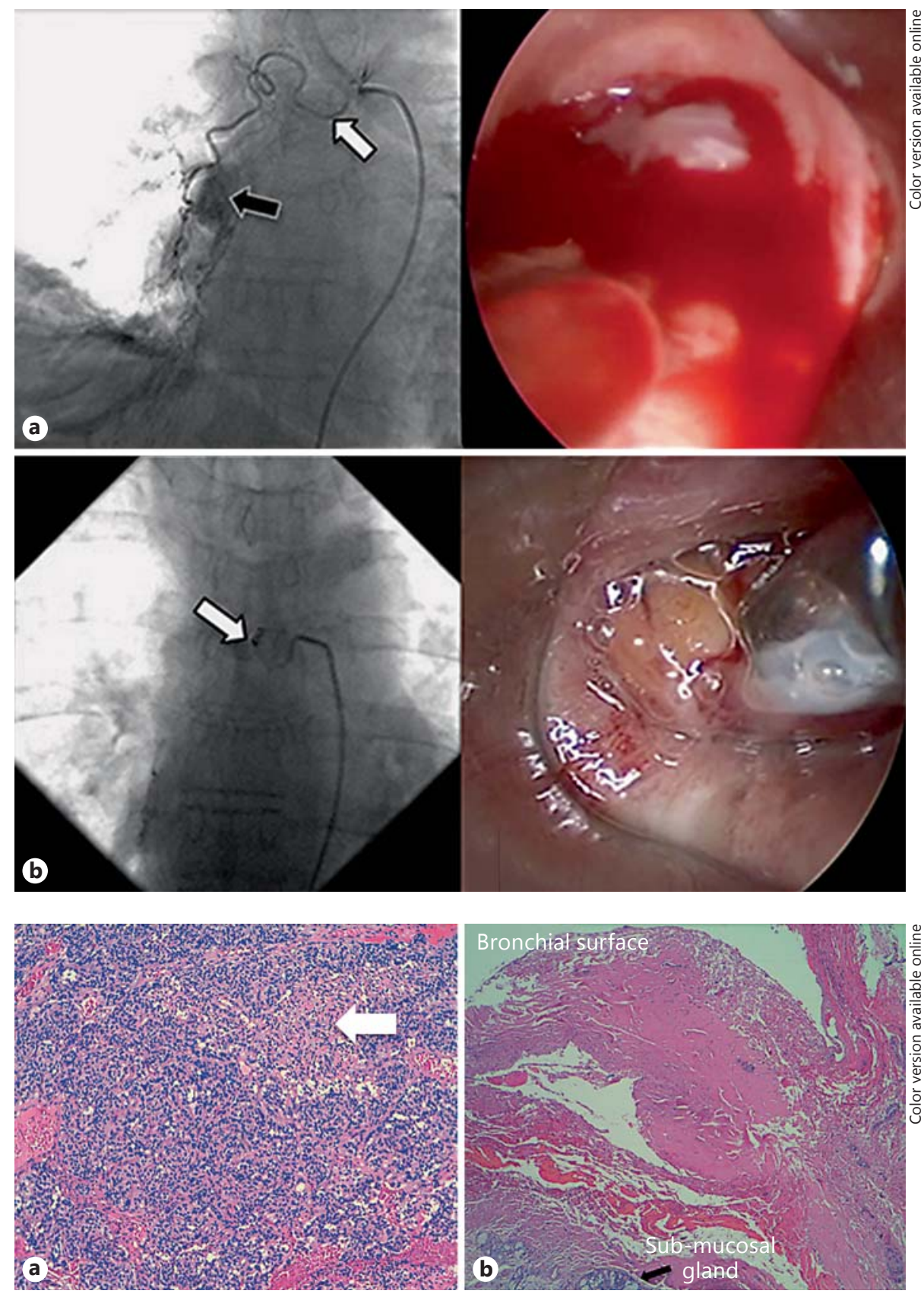

tion rate of 1.4-6.5\% [16]. Thus, one might legitimately ask whether the risk of major bleeding during the resection of a bronchial carcinoid without prior bronchial artery embolization outweighs the risk of spinal cord ischaemia with embolization. However, we feel that the benefit of pre-procedural bronchial artery embolization is not limited solely to preventing emergency surgery to control haemorrhage. We find that by markedly reducing intra-procedural bleeding, it facilitates a much faster and technically sim- pler resection. In our series of 5 patients, only 2 had more than negligible bleeding requiring repeat laser (fig. 2). It may also be possible to identify patients at risk of massive bleeding prior to the procedure, for example by visualization of an artery within the stalk or body of the tumour on CT angiography. Embolization could then be selectively performed on these patients where the benefit would be maximized. Although we advocate using rigid bronchoscopy for all cases of endobronchial carcinoid resection, we 
acknowledge that it is performed via flexible bronchoscopy in some centres [17], and the reduction in intra-procedural bleeding due to embolization may be particularly useful in this setting. Finally, the 'cure' of the single patient with atypical carcinoid in our series raises the possible utility of this combined approach in the treatment of patients with atypical bronchial carcinoid, in whom surgical resection is contra-indicated or not possible.

Arterial embolization has a proven role in the treatment of hepatocellular carcinoma [18] or hepatic metastases [19] and also in the management of metastatic extrathoracic carcinoid tumours [20,21], including hepatic spread of the highly aggressive atypical cervical carcinoid [22]. Although arterial embolization in this series was performed to reduce bleeding and facilitate endobronchial resection, it is of note that in the single case of atypical carcinoid, subsequent surgical lobectomy and lymph node dissection failed to find any evidence of residual disease. In other words, arterial embolization with endobronchial resection had resulted in local cure. The patient remains disease free after 24 months of follow-up. Clear$\mathrm{ly}$, this finding is of limited significance given that it only involved 1 case, and any implications need substantiation in larger studies. However, with the growing trend towards parenchymal-sparing resections of bronchial carcinoids [7], it is possible that, in the future, endobronchial resection of atypical carcinoid in conjunction with a technique such as arterial embolization could provide cure rates similar to surgical resection.

The lungs and airways are unique in that they receive dual blood supply, one from the systemic circulation via the bronchial arteries and one from the pulmonary circulation via the pulmonary arteries [23]. For bronchial artery embolization to serve as an aid in the resection and treatment of centrally located carcinoids, it follows that these tumours should be predominantly supplied by the bronchial arteries. This is supported by findings in a number of publications. Anatomic studies demonstrate that the trachea and mainstem bronchi derive their blood supply from the bronchial arteries [24]. As one progresses more distally, there is a rich anastomotic network between the bronchial and pulmonary systems, such that at the level of the lobar or segmental bronchi, the pulmonary circulation may account for 75-90\% of the airway blood supply [25]. In keeping with this, early lung transplants with a tracheal anastomosis between donor and recipient lung, without bronchial artery revascularization, were associated with an unacceptably high graft failure rate [26]. More recent surgical techniques, which involve sequential anastomosis of each donor lung to the distal main bronchi

Bronchial Artery Embolization and Endobronchial Resection on each side, result in much less airway ischaemic damage even in the absence of bronchial artery revascularization [27]. Finally, bronchial carcinoid tumours are derived from Kulchitsky cells which are located in the epithelial component of the bronchial mucosa [28]. While the peritracheal and adventitial tissues are supplied predominantly by the pulmonary circulation, the bronchial mucosa derives its blood supply from the bronchial arteries [23].

Successful endobronchial resection of carcinoids requires that the entire extent of the tumour is accessible in the central airways with the distal tumour margin visible to the bronchoscopist $[10,29]$. In some cases, it may be that the extra-luminal extension of the tumour, the socalled 'iceberg phenomenon', means that only a small 'tip' of the tumour is seen endoluminally, reducing the rate of complete endobronchial resection [14]. It is possible that bronchial artery embolization could induce critical ischaemia to residual tumour in the bronchial wall following resection, increasing the chance of cure. The other critical factor for successful resection is absence of extra-luminal tumour invasion [12]. Although this was assessed using high-resolution CT in our series, it should be noted that a more precise determination of tumour depth can be achieved with high-frequency $(20-\mathrm{MHz})$ endobronchial ultrasound $[30,31]$ or optical coherence tomography [32], and these should be used when available.

The major limitations of this study are the small number of patients included and the relatively short follow-up period for some participants, such that the role of embolization preceding endobronchial carcinoid resection in current clinical practice cannot be defined and no recommendations for its use can be definitively stated from this study. With a low rate of complications for both interventional bronchoscopy and bronchial artery embolization, the required study numbers would need to be very large to show a statistically significant reduction in bleeding complications. To demonstrate the facilitation of a simpler, less technically demanding procedure would require lower numbers, but objective outcome measures, such as procedure time or quantification of laser use, would need to be defined in the study design. However, this study serves as a 'proof of concept' only to demonstrate the technique's feasibility and safety. Its potential to facilitate and simplify the resection procedure may make it a useful adjuvant in the range of technical options available to the endoscopist when planning endobronchial resection of a carcinoid tumour. Finally and most importantly, it provides the impetus for further studies, which may define the patient sub-population who would benefit most from this technique, and also its applicability to patients with 
atypical carcinoid who are not operative candidates. It may be that this treatment will be restricted to a third line, when conventional surgical or endoscopic treatment is not possible or incomplete.

\section{Conclusion}

We have presented a case series demonstrating the feasibility and safety of selective bronchial artery embolization prior to endobronchial resection of bronchial carci- noids. We have found that it reduces bleeding and facilitates a safe and effective procedure. Its possible application as an adjuvant to endobronchial resection of atypical carcinoids with a curative intent warrants the design of a larger prospective clinical trial to define the benefit of such an approach.

\section{Financial Disclosure and Conflicts of Interest}

The authors declare that they have no conflicts of interest.

\section{References}

1 Tsuta K, Raso MG, Kalhor N, Liu DD, Wistuba II, Moran CA: Histologic features of low- and intermediate-grade neuroendocrine carcinoma (typical and atypical carcinoid tumors) of the lung. Lung Cancer 2011;71:34-41.

2 Beasley MB, Brambilla E, Travis WD: The 2004 World Health Organization classification of lung tumors. Semin Roentgenol 2005; 40:90-97.

3 Pinchot SN, Holen K, Sippel RS, Chen H: Carcinoid tumors. Oncologist 2008;13:1255-1269.

4 Maurizi G, Ibrahim M, Andreetti C, D'Andrilli A, Ciccone AM, Pomes LM, Menna C, Pellegrini M, Venuta F, Rendina EA: Long-term results after resection of bronchial carcinoid tumour: evaluation of survival and prognostic factors. Interact Cardiovasc Thorac Surg 2014; 19:239-244.

5 Noel-Savina E, Descourt R: Focus on treatment of lung carcinoid tumor. Onco Targets Ther 2013;6:1533-1537.

6 El Jamal M, Nicholson AG, Goldstraw P: The feasibility of conservative resection for carcinoid tumours: is pneumonectomy ever necessary for uncomplicated cases? Eur J Cardiothorac Surg 2000;18:301-306.

7 Brokx HA, Sutedja TG: Cutting edge without cutting corners: bronchoscopic treatment for bronchial carcinoids. Respiration 2011;81: 285-286.

8 Cavaliere S, Foccoli P, Toninelli C: Curative bronchoscopic laser therapy for surgically resectable tracheobronchial tumors. J Bronchol 2002;9:90-95.

-9 Jesudasan CD, Nair S, Thangakunam B, Keshava SN, Moses V: Near-fatal hemorrhage after bronchoscopic resection of a carcinoid tumor: successful management by bronchial artery embolization. J Bronchology Interv Pulmonol 2010;17:152-154.

10 Neyman K, Sundset A, Naalsund A, Espinoza A, Solberg S, Kongerud J, Fosse E: Endoscopic treatment of bronchial carcinoids in comparison to surgical resection: a retrospective study. J Bronchology Interv Pulmonol 2012; 19:29-34.
11 Brambilla E, Travis WD, Colby TV, Corrin B, Shimosato Y: The new World Health Organization classification of lung tumours. Eur Respir J 2001;18:1059-1068.

-12 Brokx HA, Risse EK, Paul MA, Grunberg K, Golding RP, Kunst PW, Eerenberg JP, van Mourik JC, Postmus PE, Mooi WJ, Sutedja TG: Initial bronchoscopic treatment for patients with intraluminal bronchial carcinoids. J Thorac Cardiovasc Surg 2007;133:973-978.

13 Juttner FM, Pinter H, Friehs G, Klepp G, Kohek P: Management of severe hemorrhage after biopsy in bronchial carcinoids. Panminerva Med 1986;28:287-288.

14 Hage R, de la Riviere AB, Seldenrijk CA, van den Bosch JM: Update in pulmonary carcinoid tumors: a review article. Ann Surg Oncol 2003; 10:697-704.

15 Larici AR, Franchi P, Occhipinti M, Contegiacomo A, Del Ciello A, Calandriello L, Storto ML, Marano R, Bonomo L: Diagnosis and management of hemoptysis. Diagn Interv Radiol 2014;20:299-309.

16 Yoon W, Kim JK, Kim YH, Chung TW, Kang HK: Bronchial and nonbronchial systemic artery embolization for life-threatening hemoptysis: a comprehensive review. Radiographics 2002;22:1395-1409.

17 Fuks L, Fruchter O, Amital A, Fox BD, Abdel Rahman N, Kramer MR: Long-term followup of flexible bronchoscopic treatment for bronchial carcinoids with curative intent. Diagn Ther Endosc 2009;2009:782961.

18 Reidy DL, Schwartz JD: Therapy for unresectable hepatocellular carcinoma: review of the randomized clinical trials - I: hepatic arterial embolization and embolization-based therapies in unresectable hepatocellular carcinoma. Anticancer Drugs 2004;15:427-437.

19 Mahnken AH, Pereira PL, de Baere T: Interventional oncologic approaches to liver metastases. Radiology 2013;266:407-430.

20 Gao J, Hu Z, Wu J, Bai L, Chai X: Primary hepatic carcinoid tumor. World J Surg Oncol 2011;9:151.
21 Ahlman H, Nilsson O, Olausson M: Interventional treatment of the carcinoid syndrome. Neuroendocrinology 2004;80(suppl 1):67-73.

22 Yoshida Y, Sato K, Katayama K, Yamaguchi A, Imamura Y, Kotsuji F: Atypical metastatic carcinoid of the uterine cervix and review of the literature. J Obstet Gynaecol Res 2011;37: 636-640.

23 Baile EM: The anatomy and physiology of the bronchial circulation. J Aerosol Med 1996;9:1-6.

24 Salassa JR, Pearson BW, Payne WS: Gross and microscopical blood supply of the trachea. Ann Thorac Surg 1977;24:100-107.

25 Frechette E, Deslauriers J: Surgical anatomy of the bronchial tree and pulmonary artery. Semin Thorac Cardiovasc Surg 2006;18:77-84.

26 Daly RC, Tadjkarimi S, Khaghani A, Banner NR, Yacoub MH: Successful double-lung transplantation with direct bronchial artery revascularization. Ann Thorac Surg 1993;56:885-892.

27 Pettersson GB, Yun JJ, Norgaard MA: Bronchial artery revascularization in lung transplantation: techniques, experience, and outcomes. Curr Opin Organ Transplant 2010;15: 572-577.

28 Wang LT, Wilkins EW Jr, Bode HH: Bronchial carcinoid tumors in pediatric patients. Chest 1993;103:1426-1428.

29 van Boxem TJ, Venmans BJ, van Mourik JC, Postmus PE, Sutedja TG: Bronchoscopic treatment of intraluminal typical carcinoid: a pilot study. J Thorac Cardiovasc Surg 1998; 116:402-406.

30 Kurimoto N, Fielding D, Musani A: Endobronchial ultrasonographic analysis of airway wall integrity and tumor involvement; in Kurimoto N, Fielding D, Musani A (eds): Endobronchial Ultrasonography. Oxford, Wiley-Blackwell, 2010, pp 96-110.

31 Tremblay A: Endobronchial ultrasonography: extending the reach of the bronchoscope beyond the airway wall. CMAJ 2003;169:586.

- 32 Ikeda N, Hayashi A, Iwasaki K, Honda H, Tsuboi M, Usuda J, Kato H: Comprehensive diagnostic bronchoscopy of central type early stage lung cancer. Lung Cancer 2007;56:295-302. 